\title{
Back analysis of an earthquake-triggered submarine landslide near the SW of Xiaoliuqiu
}

\author{
Huai-Houh $\mathrm{Hsu}^{1,2, *}$, Jia-Jyun Dong ${ }^{3}$, Shu-Kun $\mathrm{Hsu}^{4}$, and Chih-Chieh $\mathrm{Su}^{5}$ \\ ${ }^{1}$ Department of Construction Engineering, National Kaohsiung University of Science and Technology, Kaohsiung City, Taiwan \\ ${ }^{2}$ Department of Civil Engineering, Chienkuo Technology University, Changhua City, Taiwan \\ ${ }^{3}$ Graduate Institute of Applied Geology, National Central University, Taoyuan City, Taiwan \\ ${ }^{4}$ Department of Earth Sciences, National Central University, Taoyuan City, Taiwan \\ ${ }^{5}$ Institute of Oceanography, National Taiwan University, Taipei City, Taiwan
}

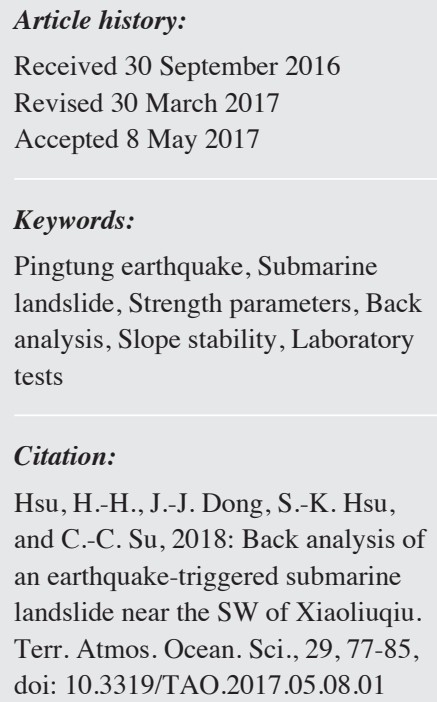

\begin{abstract}
Occurred in the offshore of SW Taiwan on 26 December 2006 with a magnitude of 7 , the Pingtung earthquake had triggered numbers of submarine landslides. This event provides an excellent opportunity to incorporate the back analysis approach to evaluate the in situ shear strength parameters. According to the chirp sonar images of the seabed near the SW Xiaoliuqiu obtained before and after the earthquake were adopted to establish the slope profile and identified the location of a circular sliding surface. Consequently, the in situ, effective strength parameters under the critical condition can be calculated by back slope stability analysis. Submarine sediment sampler was obtained via gravity sampling method and the laboratory tests were performed to determine the index properties and strength parameters. Test results indicate the cored sediment has the characteristics of normally consolidated (NC) clay. The effective friction angle $\left(\phi^{\prime}\right)$ is $15.3^{\circ}$ with cohesion $\left(c^{\prime}\right)$ of $19.4 \mathrm{kPa}$. The effective and total stress methods were used to perform the back analysis. The strength parameters derived from back analysis of effective and total stress methods all indicate values approach the CIU triaxial tests results. Consequently, the representativeness of the marine sediment characteristics obtained from laboratory tests is identified. The total stress approach yields an undrained strength ratio $c_{u} / \sigma^{\prime}{ }_{v 0}$ of 0.26 which well fit the ratio used in geotechnical practice for estimating NC clay. According to the analytical approach, the landslide was applied seismic forces (seismic coefficient $k_{h}=0.14$ ) and generated excess pore pressure of $31 \mathrm{kPa}$ at the sliding surface.
\end{abstract}

\section{INTRODUCTION}

As the requirement of energy exploration, the technique of offshore geotechnical testing has been developed in the early 1970's (Van Den Berg 1984), and its capability can reach deepwater over than 3000 m nowadays (Lunne 2010). There has been substantial evidence indicating that the south west (SW) off Taiwan is rich in gas hydrate fields. To explore these energy resources, the slope stability and landslide issue should be considered carefully. The gas hydrate disassociation leads to volume expansion rapidly and even reaches 150 to 170 times of its original volume under the conditions of $1 \mathrm{~atm}$ and $20^{\circ} \mathrm{C}$. This process causes submarine landslide

\footnotetext{
* Corresponding author

E-mail: geolab.hsu@outlook.com
}

and results in geohazard events such as debris flow, slump, and slide (Kvenvolden 1993; Paull et al. 1996). The case of Storegga slide was supposed to be initiated by gas hydrate disassociation as a result of sea level lowering, developed a total volume of near $5000 \mathrm{~km}^{3}$ sliding body and generated tsunamis (Harbitz 1992; Locat and Lee 2002). Hampton et al. (1996) presented a detail description and discussion about the characteristics and failure mechanisms of submarine landslides. As they pointed out, the detailed site investigation must be performed for evaluating slope stability during the planning and design stages of submarine structures. Among others, characterizing the shear strength of offshore sediments is essential to evaluate the slope stability problems related to the use of natural energy resources. Randolph (2004) reviewed practice and potential advances in characterizing the 
soft sediments typically encountered in deepwater offshore developments. However, the representativeness of the laboratory tests has been questioned frequently for the complexity of the in-situ conditions. Obviously, it is a challenge to assess the in-situ sediment strength offshore with water depth approaches to hundreds meters. Occurred in the offshore of SW Taiwan $\left(21.97^{\circ} \mathrm{N}, 120.42^{\circ} \mathrm{E}\right)$ on 26 December 2006 by a magnitude of 7.0 and had a hypocentral depth of $50.2 \mathrm{~km}$, the Pingtung earthquake had triggered numbers of submarine landslides and damaged telecommunication cables on the seafloor (Hsu et al. 2008).

This event provides an excellent opportunity to incorporate the back analysis approach of slope stability to evaluate the representative in situ strength of sediments. In this study, two chirp sonar images near the SW of Xiaoliuqiu before and after the Pingtung earthquake are adopted to identify the profile before and after the sliding surface. A comprehensive site investigation project was carried out to characterize the submarine sediments of the SW of Xiaoliuqiu. Sampler cored from this region is used to perform laboratory tests to obtain the physical properties and strength parameters of marine sediments. According to the contrast sonar images pre- and post-earthquake event, the back analysis of slope stability can therefore be performed without difficulty. Strength parameters determined from back analysis and triaxial CIU tests will be compared. Accordingly, the representativeness of the marine sediments strength from laboratory CIU test can be testified.

\section{STUDY AREA}

The studied submarine landslide is located in the SW of Xiaoliuqiu (Fig. 1) near the Kaoping canyon. We are lucky enough to have two chirp sonar images of the seabed near the earthquake triggered landslide site before (29 September 2006, Fig. 1a) and after (8 January 2007, Fig. 1b) the Pingtung earthquake, hence the sliding surface can be identified clearly (red dashed rectangle in Fig. 1).

The failure slope is dipping toward to the north-western direction. The slope angle of the north-westward slope gradually increased from about $1^{\circ} \sim 2^{\circ}$ to $7^{\circ} \sim 10^{\circ}$. Based on Fig. 1b, we can clearly identify the crown and deposition zone of the submarine landslide. The deposition zone and the inferred source zone are illustrated in Fig. 2. Table 1 shows a summary of the landslide geometry. The maximum thickness of the deposition is about $30 \mathrm{~m}$. The height $(\mathrm{H})$ and length $(\mathrm{L})$ of the submarine landslide are about 30 and $400 \mathrm{~m}$ respectively. The run-out distance $\left(\delta_{r d}\right)$ is about $300 \mathrm{~m}$. Accordingly, part of the sliding surface was still covered by the moved mass. We reconstructed the seabed before slope failure mainly based on the pre-failure topography (Fig. 1a). The averaged slope angle $(\alpha)$ of the failed slope is about $4.2^{\circ}$. The maximum thickness $\left(h_{\max }\right)$ of the submarine landslide is about $16 \mathrm{~m}$ and has an average thick- ness $\left(h_{\text {avg }}\right)$ of $11 \mathrm{~m}$, which is less than the maximum deposition depth. It is interesting to be observed that the white line in Fig. $1 \mathrm{~b}$ is quite smooth above the toe of the studied landslide but relatively irregular below the toe. We speculated that the mass movement scouring the original smooth seabed. It is assumed that the original seabed is higher, as indicated in Fig. 2. Notably, the deposition area in Fig. 2 is slightly greater than the one of source area, which indirectly shows the reasonableness of the landslide model. It is a pity that the lateral information is inadequate to reconstruct the 3 dimensional geometry of the submarine landslide. However, it is adequate for back analyzing the strength of the marine deposits since the 3 dimensional effect is not significant (Ten Brink et al. 2009).

\section{SOIL LABORATORY TESTING OF SUBMARINE SEDIMENTS}

In order to determine in situ soil characteristics around study area, a location was planned to obtain sampler of submarine sediments. The cored site is about $1 \mathrm{~km}$ south of this landslide area and core will be taken along the same isobath (red dot in Fig. 1).

The gravity coring and box coring are mainly used methods for offshore site investigation in Taiwan. The gravity coring method is performed by a cast iron tube sampler to obtain soil corer sample. The cast iron tube sampler consists of a driving shoe at the bottom, cast iron tube in the middle, a heavy weight at the top, and an acrylic tube inside the iron tube. The cast iron tube sampler will be lowered down to a height above the seafloor, be dropped in a free fall style, and penetrates into the seabed until the resistance force of the sampler exhausted the driving force. A sediment corer sample of $2-5 \mathrm{~m}$ long can generally be obtained. Because of a very high speed penetration before coring, the sample disturbance is obvious. The box coring method is a better way for obtaining low disturbed soil corer samples. But the box corer can only reach a very shallow depth to get sediments on the submarine surface. Soil corer sample at a deeper depth below seedbed surface was required in this study. As a result, the gravity coring method was adopted and a length of $2 \mathrm{~m}$ sediment corer sample was taken (core No. C, red dot in Fig. 1).

The disturbance of soil specimen comes from two processes before performing laboratory tests: (1) in situ sampling method; (2) specimen removed from sampler. As described above, the disturbance resulted from gravity coring method is inevitable. In this study, a well performing technique has been developed to remove specimen from sampler and avoids further disturbance before carrying out laboratory tests. Instead of using the ordinary piston tube procedure to push cylindrical soil specimen from sampler tube by a hydraulic jack, the very soft clay is removed by a pressurized air cushion technique to reduce disturbance. 

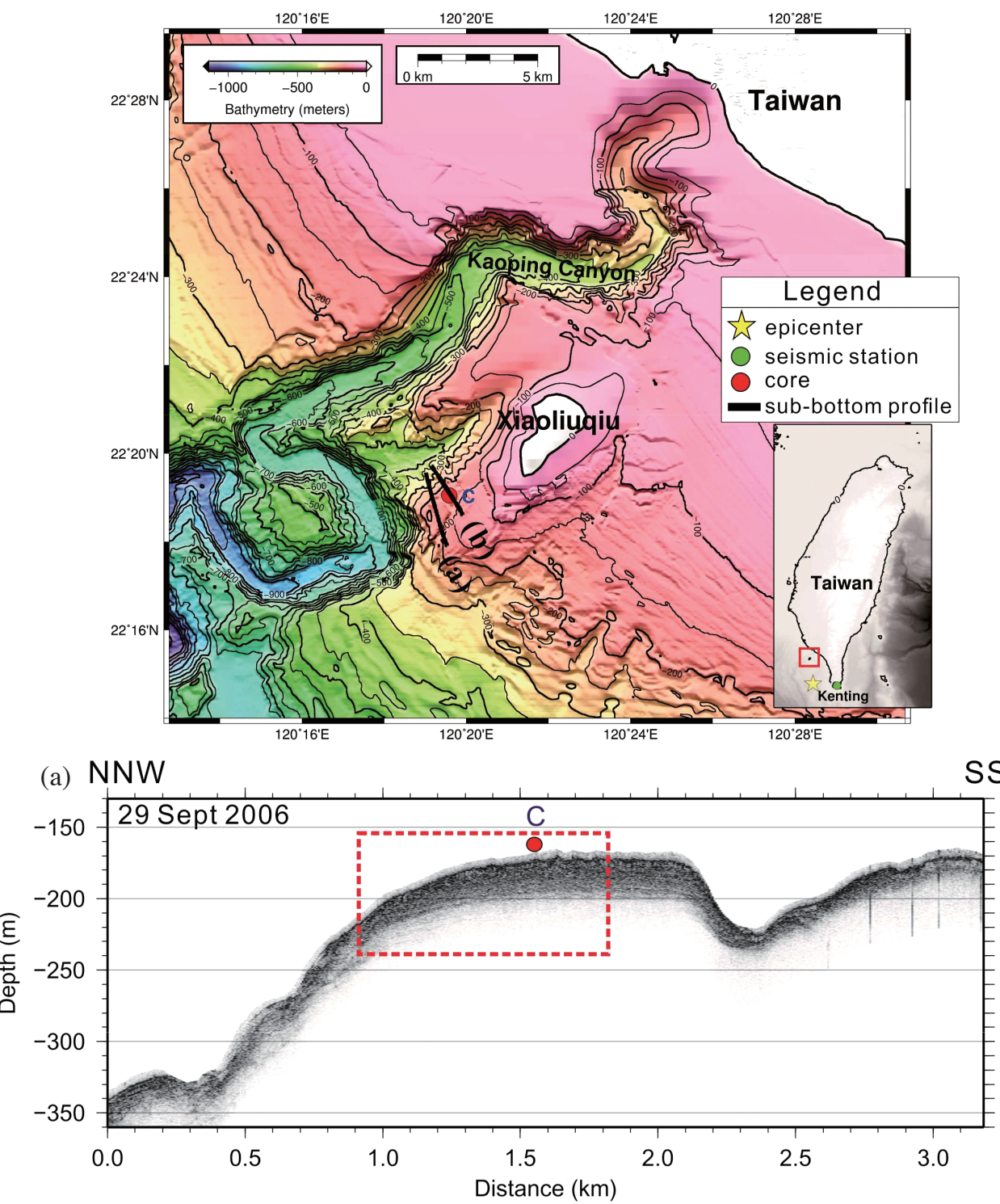

(b) NNW

SSE

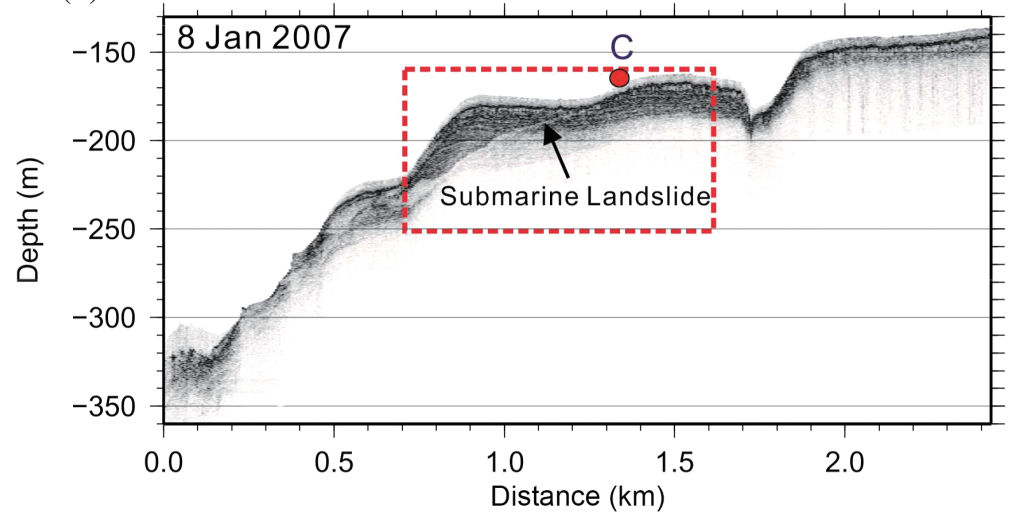

Fig. 1. Upper picture: detail bathymetry near the SW Xiaoliuqiu of offshore SW Taiwan. Upper right picture: an index map of study area and epicenter (a yellow star) of the Pingtung earthquake on 26 December 2006. Middle and Lower pictures: chirp sonar images of the seabed before and after the 2006 Pingtung earthquake and locations are indicated as (a) and (b) respectively. The red dashed rectangle indicates the area was used for slope analysis. 


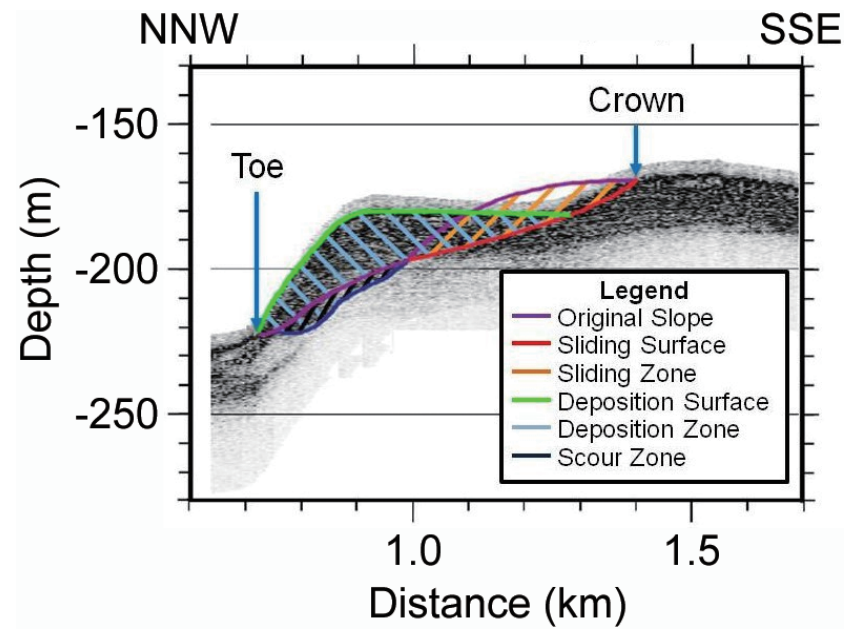

Fig. 2. Schematic geomorphological cross section of the landslide region.

Table 1. Landslide geometry.

\begin{tabular}{cccccccc}
\hline $\begin{array}{c}\text { Failure } \\
\text { Mode }\end{array}$ & $\boldsymbol{\alpha}(\mathbf{d e g})$. & $\mathbf{L}(\mathbf{m})$ & $\mathbf{H}(\mathbf{m})$ & $\mathbf{L} / \mathbf{H}$ & $\boldsymbol{h}_{\max }(\mathbf{m})$ & $\boldsymbol{h}_{\text {avg }}(\mathbf{m})$ & $\boldsymbol{\delta}_{\boldsymbol{r d}}(\mathbf{m})$ \\
\hline Circular & 4.2 & 410 & 30 & 13.7 & 16 & 11 & 300 \\
\hline
\end{tabular}

Note: * $\alpha$ is the average slope angle of landslide body.

The laboratory work was planned in order to construction the index properties and strength parameters. The index properties were obtained by physical property tests and $\mathrm{X}$-ray diffraction analysis (XRD). The strength parameters were determined by the effective stress path method of triaxial tests. All tests were carried out according to ASTM. Test results are presented and discussed below.

\subsection{Index Properties}

Table 2 summarizes physical properties of core No. C. According to the Unified Soil Classification System (USCS), the sediment sampler is classified into low plasticity silty soils (ML). The mass unit weight $(\gamma)$ is $16.97 \mathrm{kN} \mathrm{m}^{-3}$. The specific gravity $\left(G_{s}\right)$ of 2.85 is compatible with typical values of fine grained soils. In addition to a high porosity $(n=58 \%)$, the natural water content $\left(\omega_{n}=43 \%\right)$ is higher than Atterberg's liquidity limit $(L L=37 \%)$, which reveals a very soft soil material characters and soil plasticity behavior should be considered.

Figure 3 illustrates the grain size distribution curve and results of X-ray diffraction analysis (XRD) of core No. C. The mass fraction of silt and clay are 70 and 30\% respectively. Results of XRD analyses display plasticity behavior of mineralogical characteristics. The clay fraction consists mostly of quartz, plagioclase, illite and chlorite. The quartz appears a predominant mineral. The activity $\left(A_{c}\right)$ is consid- ered low with a value of 0.3 which is between typical values of kaolinite and quartz.

\subsection{Strength Parameters}

The isotropically consolidated undrained (CIU) triaxial tests were performed to establish the effective stress path during axial compression and hence determined the strength parameters. The triaxial specimens were sheared by axial compression under undrained condition with excess pore pressure $\left(u_{e}\right)$ measurements. A total of three triaxial tests were performed with combinations of three levels of confining pressure $\left(\sigma_{c}=100 \sim 480 \mathrm{kPa}\right)$.

Figure 4 illustrates effective stress paths, deviator stress $\left(\sigma_{d}\right)$ against axial strain $\left(\varepsilon_{a}\right)$ curves, excess pore pressure $\left(u_{e}\right)$ against axial strain $\left(\varepsilon_{a}\right)$ curves, and deformed shape of specimens. According to the developed behavior of $\sigma_{d}-\varepsilon_{a}$ curve, the typical curve of a normally consolidated clay (NC clay) is observed where $\sigma_{d}$ arrived at an almost plateau state after a large $\varepsilon_{a}$. The associated variation of positive $u_{e}$ value also shows compression behavior during shearing for NC clay. The linear equation of $K_{f}$ line determined by the critical state of effective stress paths and is used to derive strength parameters of cohesion $\left(c^{\prime}\right)$ and effective friction angle $\left(\phi^{\prime}\right)$. As shown in Table 3, strength parameters of core No. C are $c^{\prime}=19.4 \mathrm{kPa}$ and $\phi^{\prime}=15.3^{\circ}$.

The undrained strength ratios $\left(c_{u} / \sigma_{v 0}^{\prime}\right)_{\mathrm{CIU}}$ of undrained shear strength $\left(c_{u}\right)$ over effective overburden stress $\left(\sigma_{v 0}^{\prime}\right)$ are between 0.25 and 0.4 (Table 3 ) which agree well with the suggested values of NC Clay (Lambe and Whitman 1969; Ameratunga et al. 2016). The deformed shapes of specimens show compressive failure modes and very clear shear surfaces are observed with the shearing plane angles $(\Psi)$ between $56-62^{\circ}$ (Fig. 4). The unconsolidated undrained (UU) triaxial tests were also performed. The similar undrained shear strength values (Table 3, $S_{u}=14$ and $16 \mathrm{kPa}$ ) are obtained at two different confining pressure levels which behaves as a very soft clay.

\section{SLOPE STABILITY BACK ANALYSIS}

In this study, two chirp sonar images of the Pingtung earthquake are adopted to identify the location of sliding surface (Fig. 1). Back analyzing this submarine landslide is worthwhile to obtain the representative shear strength of the sliding surface. Since the three dimensional information is lacking, we assumed the sliding surface shown in Fig. 2 is the most critical one. It indicates that the studied landslide resulted in a circular failure mode (Fig. 2). Utilizing the widely used software for slope stability (STABLE) by modified Bishop method, the effective strength parameters under the critical condition (i.e., safety factor FS $=1$ ) can be calculated. As a result of the $\mathrm{L} / \mathrm{H}(=13.7)$ of landslide body is greater than 10 (Table 1), an infinite slope analysis is also 
Table 2. Physical properties.

\begin{tabular}{cccccccccccc}
\hline Core No. & USCS & $\boldsymbol{\gamma}\left(\mathrm{kN} \mathrm{m}^{-3}\right)$ & $\mathbf{G}_{\mathbf{s}}$ & $\mathbf{n}(\boldsymbol{\%})$ & $\boldsymbol{\omega}_{\mathbf{n}}(\boldsymbol{\%})$ & PL $(\boldsymbol{\%})$ & $\mathbf{L L}(\boldsymbol{\%})$ & PI & $\mathbf{A}_{\mathbf{c}}$ & Silt $(\boldsymbol{\%})$ & Clay $(\boldsymbol{\%})$ \\
\hline $\mathrm{C}$ & $\mathrm{ML}$ & 16.97 & 2.85 & 58 & 43 & 28 & 37 & 9 & 0.3 & 70 & 30 \\
\hline
\end{tabular}

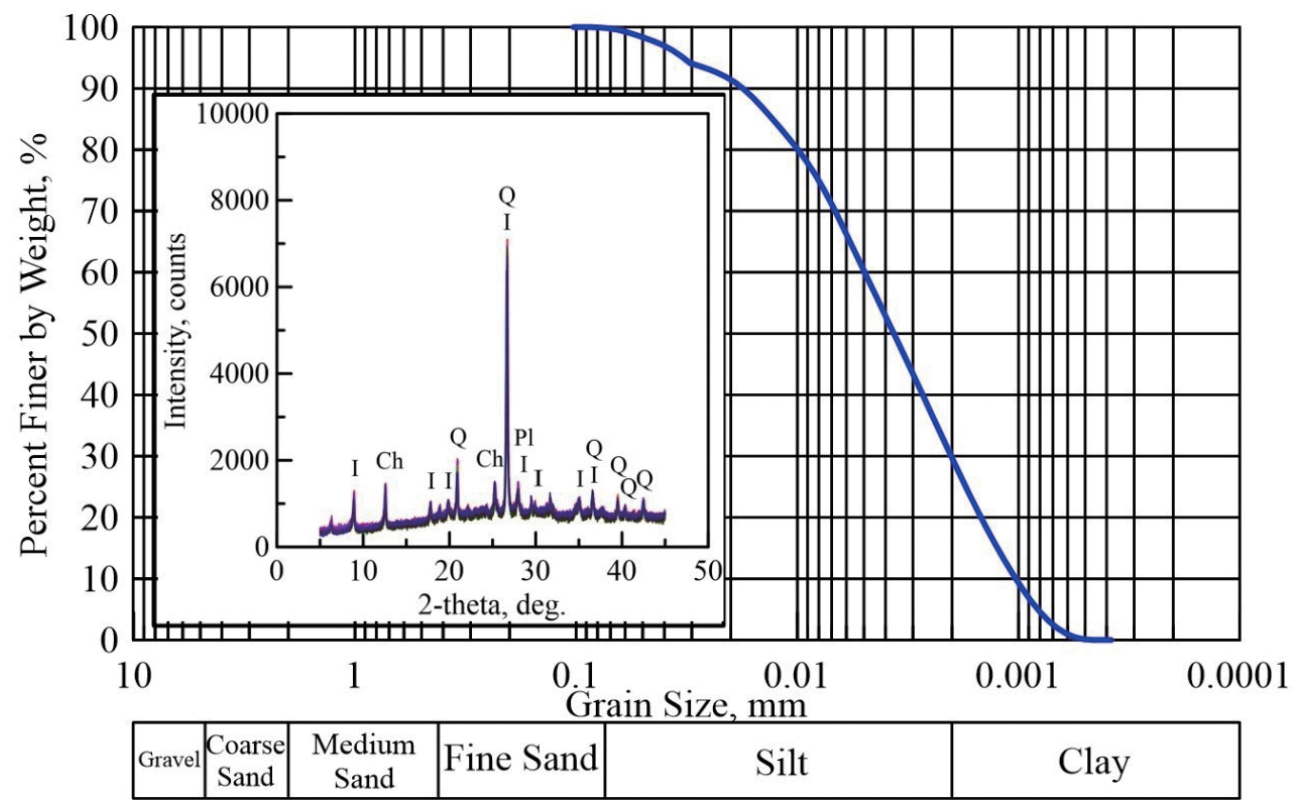

Fig. 3. Grain size distribution curve and X-ray diffraction analysis [where Q (quartz), I (illite), Ch (chlorite), and Pl (plagioclase)] of core No. C.

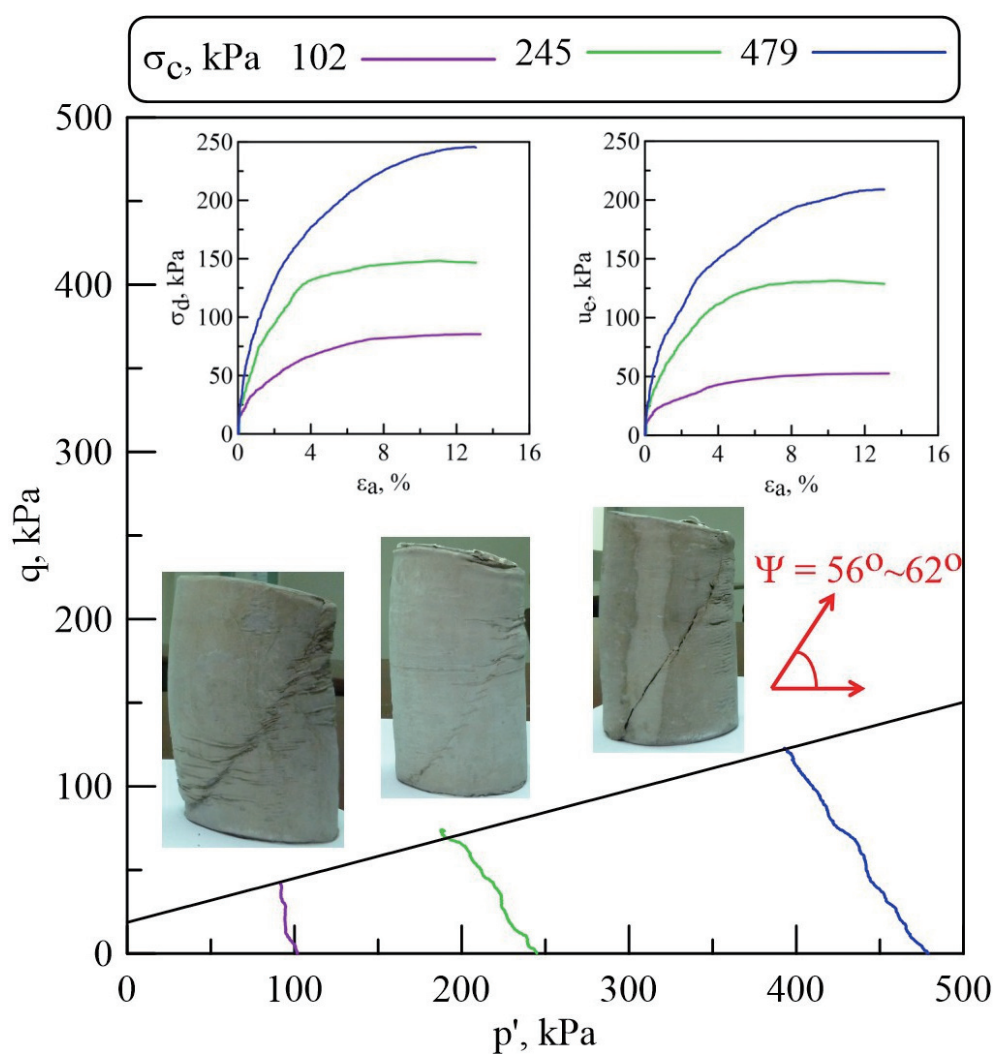

Fig. 4. Sheared soil specimens and stress curves of CIU triaxial tests (core No. C). 
Table 3. Summary of the drained and undrained strength parameters of triaxial tests.

\begin{tabular}{c|c|c|c|c|c|c|c|c|c}
\hline \multirow{2}{*}{ Core No. } & \multirow{2}{*}{$\boldsymbol{c}^{\prime}(\mathbf{k P a})$} & \multirow{2}{*}{$\boldsymbol{\phi}^{\prime}(\mathbf{d e g})}$. & & \multicolumn{3}{|c|}{$\left(\boldsymbol{c}_{u} / \boldsymbol{\sigma}_{v 0}^{\prime}\right)_{\mathrm{IU}}$} & & \multicolumn{2}{c}{$S_{u}(\mathbf{k P a})$} \\
\cline { 4 - 9 } & & & at $\boldsymbol{\sigma}_{v 0}^{\prime}=(\mathbf{k P a})$ & $\mathbf{1 0 2}$ & $\mathbf{2 4 5}$ & $\mathbf{4 7 9}$ & at $\boldsymbol{\sigma}_{c}=(\mathbf{k P a})$ & $\mathbf{2 5}$ & $\mathbf{9 4}$ \\
\hline $\mathrm{C}$ & 19.4 & 15.3 & & 0.40 & 0.29 & 0.25 & & 16 & 14 \\
\hline & & & Avg. & \multicolumn{3}{|c|}{0.31} & Avg. & \multicolumn{2}{|c}{15} \\
\hline
\end{tabular}

adopted to back calculate the strength parameters. For an infinite slope stability analysis, we can use the effective stress method to derive the limit equilibrium equation. The FS can be expressed as follows:

$$
F S=\frac{c^{\prime}+\left[\gamma^{\prime} \cdot z \cdot \cos \alpha\left(\cos \alpha-\frac{r}{r^{\prime}} k_{h} \sin \alpha\right)-u_{e}\right] \tan \phi^{\prime}}{r^{\prime} \cdot z \cdot \cos \alpha\left(\sin \alpha+\frac{r}{r^{\prime}} k_{h} \cos \alpha\right)}
$$

where $\gamma$ and $\gamma^{\prime}$ are the mass unit weight and submerged unit weigh respectively, $\alpha$ is an infinite slope angle, $k_{h}$ denotes the horizontal pseudo-static seismic coefficient, $z$ represents the depth to the failure plane, $u_{e}$ is the excess pore pressure exist at the depth $z$, and the strength parameters are $c^{\prime}$ and $\phi^{\prime}$. Setting $F S=1$ as the failure condition, the effective strength parameters can be determined by Eq. (1).

The input data included landslide profile, mass unit weight $\left(\gamma=16.97 \mathrm{kN} \mathrm{m}^{-3}\right)$, and seismic coefficients for pseudo-static analysis related to the Pingtung earthquake (Central Weather Bureau, Rec. No. 95107). The seismic coefficients were initially determined according to the records of Kenting seismic station (Fig. 1). The used horizontal pseudo-static seismic coefficient $\left(k_{h}=0.08\right)$ is a resultant value combined EW and NS accelerations along the landsliding direction. Because the slope angle of landslide $(\alpha$ $\left.=4.2^{\circ}\right)$ is gentle, the vertical pseudo-static seismic coefficient $\left(k_{v}\right)$ is assumed to be 0 . However, seismic site effects to amplify the seismic waves in soft sediments will cause a higher seismic coefficient than $k_{h}=0.08$ recorded at Kenting seismic station. The $k_{h}=0.08$ is used as the first step estimation of the strength parameters. The influence of $k_{h}$ will be discussed later.

The back calculated of STABLE and infinite slope analysis may obtain many different pairs of $c^{\prime}$ and $\phi^{\prime}$ (i.e., a given $c^{\prime}$ value obtains a $\phi^{\prime}$ ). Consequently, a further judgement should be made to decide reasonable strength parameters. For the back calculated of STABLE with the input $k_{h}$ of 0.08 and $u_{e}=0$, the obtained $\left(c^{\prime}, \phi^{\prime}\right)$ varies between $\left(0,14.7^{\circ}\right)$ and $(19.5 \mathrm{kPa}, 0)$. The very approximate results are also determined by infinite slope analysis (Table 4). Assumed $k_{h}=0.08$ to 0.14 and $u_{e}=0$, Fig. 5 demonstrates the strength parameters back calculated by these two different effective stress analyses, results indicate a very small difference between each other. Accordingly, the use of infinite slope analysis is reasonable for the present landslide event. Hereafter, we will consider that the strength parameters are back calculated only by infinite slope analysis.

In comparison with the CIU triaxial test results of core No. C (brown dot in Fig. 5) under $k_{h}=0.08$ condition, the back calculated analysis have obviously lower strength parameters. The lower values probably came from amplified seismic site effects and/or generated $u_{e}$ during earthquake.

In order to evaluate the seismic site effects individually (i.e., let $u_{e}=0$ ), the $k_{h}=0.1$ and 0.14 are used in the back calculated analysis [Eq. (1)]. The results show strength parameters approach towards CIU triaxial test results of core No. C when $k_{h}=0.14$ (Fig. 5).

The generated $u_{e}$ may be caused by ocean wave induced bottom pressure, gas generated, and earthquake (Poulos 1988). Under the same seismic coefficient $\left(k_{h}=0.08\right)$, the different $u_{e}(=30,40$, and $50 \mathrm{kPa})$ are applied to the infinite slope analysis [Eq. (1)] and results shown reasonable approach curves to the strength parameters of core No. C while $u_{e}$ increasing (Fig. 6).

If the factors of $k_{h}$ and $u_{e}$ are taken into consideration simultaneously, the increasing of $k_{h}$ accompany with reducing $u_{e}$ are obtained for given strength parameters (Fig. 7). If the sliding surface is assumed to exist the same strength parameters as core No. C, Table 5 shows four components of $k_{h}$ and $u_{e}$ deduced from infinite slope analysis. For each component, the $k_{h}$ and $u_{e}$ are observed to fall in the reasonable ranges. Accordingly, the strength parameters of CIU triaxial test results have the representatives of sliding surface.

We also performed back analyses using total stress approach. Under the critical state of limit equilibrium, the undrained strength ratio is given by (Ten Brink et al. 2009):

$\frac{c_{u}}{\sigma_{v 0}^{\prime}}=\cos \alpha \cdot \sin \alpha+k_{h} \cdot\left(\frac{\gamma}{\gamma^{\prime}}\right) \cos ^{2} \alpha$

where $\gamma$ and $\gamma^{\prime}$ are the mass unit weight and submerged unit weigh respectively, $\alpha$ is an infinite slope angle, $k_{h}$ denotes the horizontal pseudo-static seismic coefficient, $\sigma_{v 0}^{\prime}$ is effective overburden stress at the failure plane, and $c_{u}$ is the undrained shear strength.

Table 6 illustrates the $\left(c_{u} / \sigma_{v 0}^{\prime}\right)$ values under different $k_{h}$ conditions by performing back analysis of Eq. (2). When 
Table 4. Comparison of back calculated strength parameters based on finite and infinite slope stability analysis (at $k_{h}=0.08$ and $u_{e}=0$ ).

\begin{tabular}{c|c|c}
\hline \multirow{2}{*}{ Method } & \multicolumn{2}{|c}{ Strength Parameters } \\
\cline { 2 - 3 } & $\boldsymbol{c}^{\prime}$ (kPa) & $\boldsymbol{\phi}^{\prime}$ (deg.) \\
\hline \multirow{3}{*}{ Modified Bishop } & 0 & 14.7 \\
& 9 & 8 \\
& 19.5 & 0 \\
\hline \multirow{2}{*}{ Inifinite Slope [Eq. (1)] } & 0 & 14.9 \\
& 9 & 8.5 \\
& 20.6 & 0 \\
\hline
\end{tabular}

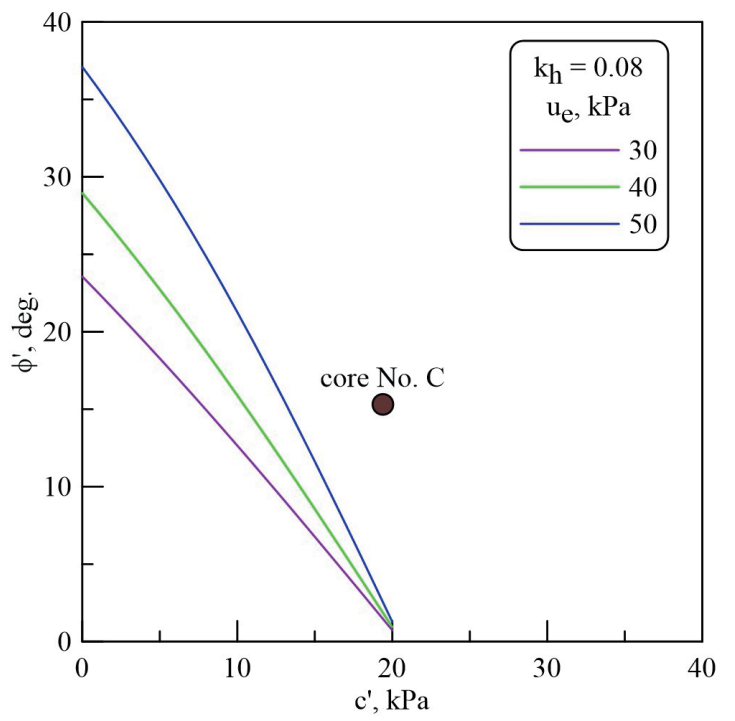

Fig. 6. Strength parameters obtained by back calcluation of infinite slope analysis under a constant $k_{h}$ and different $u_{e}$ conditions.

Table 5. Back calculated $k_{h}$ and $u_{e}$ under $c^{\prime}=19.4 \mathrm{kPa}$ and $\phi^{\prime}=15.3^{\circ}$ using Eq. (1).

\begin{tabular}{cc}
\hline $\boldsymbol{k}_{\boldsymbol{h}}$ & $\boldsymbol{u}_{\boldsymbol{e}}(\mathbf{k P a})$ \\
\hline 0.08 & 73 \\
0.1 & 59 \\
0.12 & 45 \\
0.14 & 31 \\
\hline
\end{tabular}

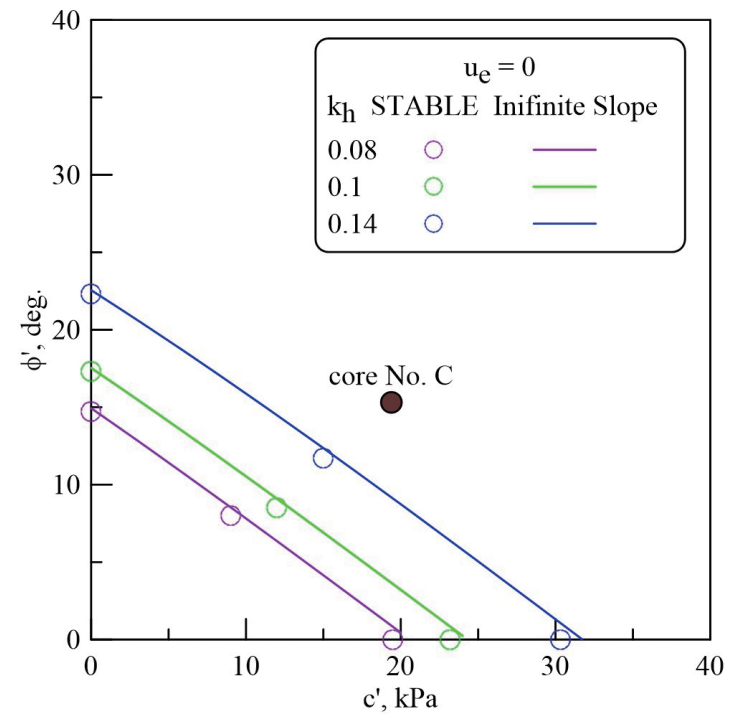

Fig. 5. Comaprison of strength parameters obtained by STABLE and infinite slope analysis at $u_{e}=0$ condition.

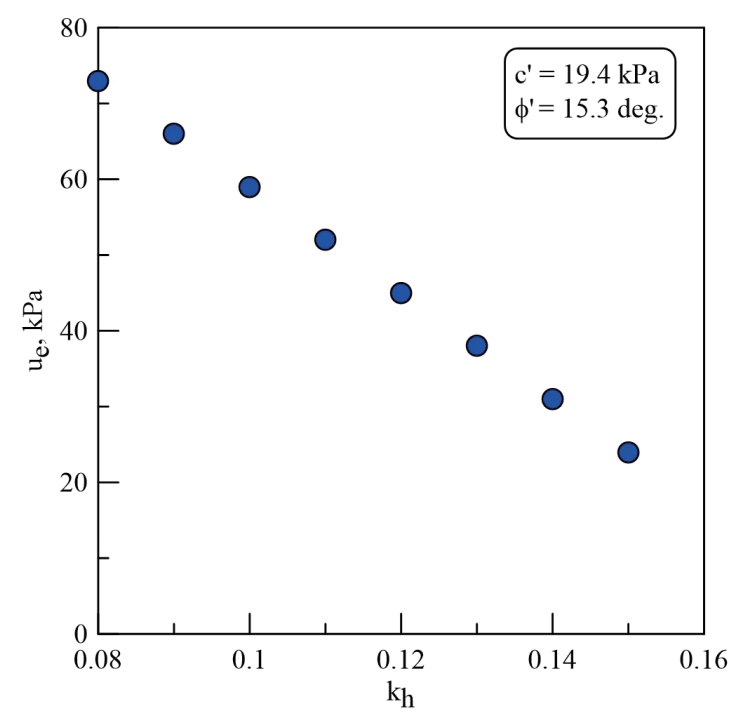

Fig. 7. Correlation between $k_{h}$ and $u_{e}$ under a known strength parameters condition.

Table 6. Back calculated $\left(c_{u} / \sigma_{v 0}^{\prime}\right)$ under a given $k_{h}$ condition using Eq. (2).

\begin{tabular}{cc}
\hline $\boldsymbol{k}_{\boldsymbol{h}}$ & $\left(\boldsymbol{c}_{u} / \boldsymbol{\sigma}_{v 0}^{\prime}\right)$ \\
\hline 0.08 & 0.26 \\
0.1 & 0.31 \\
0.12 & 0.36 \\
0.14 & 0.40 \\
\hline
\end{tabular}


$k_{h}=0.08$, we can obtain $\left(c_{u} / \sigma_{v 0}^{\prime}\right)$ of 0.26. This $\left(c_{u} / \sigma_{v 0}^{\prime}\right)$ value is between the suggested range of 0.2 and 0.4 for $\mathrm{NC}$ clay (Lambe and Whitman 1969; Ameratunga et al. 2016), but is smaller than the average $\left(c_{u} / \sigma_{v 0}^{\prime}\right)_{\mathrm{CIU}}$ of 0.31 obtained by CIU triaxial tests (Table 3 ). Assuming sliding surface is at depth of $h_{\text {avg }}(=11 \mathrm{~m})$, the initial effective overburden stress $\left(\sigma_{v i}^{\prime}\right)$ is $79 \mathrm{kPa}$ in the sliding plane of infinite slope. As shown in Table 3 , the highest $\left(c_{u} / \sigma_{v 0}^{\prime}\right)_{\mathrm{CIU}}(=0.4)$ is obtained under the conditions of $\sigma_{v 0}^{\prime}=102 \mathrm{kPa}$ which stress level is much approximate the $\sigma_{v i}^{\prime}$. Substituting $\left(c_{u} / \sigma_{v 0}^{\prime}\right)_{\mathrm{CIU}}$ $=0.4$ in Eq. (2), the $k_{h}=0.14$ is obtained. This $k_{h}$ agrees with the back calculated results of effective stress analysis.

Based on the above discussion, the back analyzed strength parameters are identical to the laboratory testing results when an amplified seismic coefficient of $k_{h}=0.14$ is used and generating excess pore pressure $u_{e}=31 \mathrm{kPa}$ on the sliding plane. That is, the CIU testing results adopting shallow depth samples below the seabed is representative for the submarine landslide with a maximum depth of $30 \mathrm{~m}$.

\section{CONCLUSIONS}

According to chirp sonar images were got from before and after 2006 Pingtung earthquake event, an apparent landslide profile was observed and provides an opportunity to evaluate the issue of seabed slope stability. Both methods of backward slope stability analysis and laboratory soil tests are performed and their results are discussed, the conclusions can be made as follows.

(1) The $2 \mathrm{~m}$ long corer sample of submarine sediments was taken near the seabed surface and carried out laboratory tests. Test results show the characters of very soft NC clay. The strength parameters of $c^{\prime}$ and $\phi^{\prime}$ are $19.4 \mathrm{kPa}$ and $15.3^{\circ}$ respectively.

(2) Due to high ratio of $\mathrm{L} / \mathrm{H}(=13.7)$, the strength parameters obtained from finite slope or infinite slope method show approximate values.

(3) The back calculated of effective stress analysis obtained slightly lower strength parameters than CIU test results. However, if the amplified seismic site effects in soft submarine sediments and generating $u_{e}$ during earthquake are considered, the back calculated strengths will close to the ones obtained from CIU tests.

(4) The total stress analysis at $k_{h}=0.08$ yields the back calculated undrained strength ratio $\left(c_{u} / \sigma_{v 0}^{\prime}\right)$ of 0.26 . This value is well within the range of NC clay $(0.2-0.4)$. If the seismic site effects in soft submarine sediments are considered, the back calculated values may be approximated CIU test results (averaged value of undrained strength ratio $=0.31$ ).

(5) The back analyzed strength parameters will be identical to the laboratory testing results when a seismic coefficient of $k_{h}=0.14$ and generating excess pore pressure $u_{e}$ $=31 \mathrm{kPa}$ on the sliding plane are assumed.
(6) The laboratory test results of gravity corer samples are representative with respect to the slope stability analysis of a sliding body less than $30 \mathrm{~m}$ depth. However, for a sliding surface at deeper depth, the representativeness of corer samples near seabed surface yet remains a further research and discussion.

Acknowledgements The work presented in this paper was made possible through the support of the Ministry of Science and Technology, R.O.C. under grants of MOST 103-3113M-008-001 and MOST 104-3113-M-008-001. Their supports are gratefully appreciated. Two reviewers, who provided constructive comments, are highly grateful for their suggestions greatly improve the quality of our manuscript.

\section{REFERENCES}

Ameratunga, J., N. Sivakugan, and B. M. Das, 2016: Correlations of soil and rock properties in geotechnical engineering, Springer India Publ., New Delhi, 228 pp, doi: 10.1007/978-81-322-2629-1. [Link]

Hampton, M. A., H. J. Lee, and J. Locat, 1996: Submarine landslides. Rev. Geophys., 34, 33-59, doi: 10.1029/95RG03287. [Link]

Harbitz, C. B., 1992: Model simulations of tsunamis generated by the Storegga slides. Mar. Geol., 105, 1-21, doi: 10.1016/0025-3227(92)90178-K. [Link]

Hsu, S. K, J. Kuo, C. L. Lo, C. H. Tsai, W. B. Doo, C. Y. $\mathrm{Ku}$, and J. C. Sibuet, 2008: Turbidity currents, submarine landslides and the 2006 Pingtung earthquake off SW Taiwan. Terr. Atmos. Ocean. Sci., 19, 767-772, doi: 10.3319/TAO.2008.19.6.767(PT). [Link]

Kvenvolden, K. A., 1993: Gas hydrates - geological perspective and global change. Rev. Geophys., 31, 173187, doi: 10.1029/93RG00268. [Link]

Lambe, T. W. and R. V. Whitman, 1969: Soil Mechanics, SI Version, John Wiley \& Sons, 576 pp.

Locat, J. and H. J. Lee, 2002: Submarine landslides: advances and challenges. Can. Geotech. J., 39, 193-212, doi: 10.1139/t01-089. [Link]

Lunne, T., 2010: The CPT in offshore soil investigations - a historic perspective. Proceedings of the 2nd International Symposium on Cone Penetration Testing, Huntington Beach, California, USA, 1(KN4), 1-43.

Paull, C. K., W. J. Buelow, W. Ussler III, and W. S. Borowski, 1996: Increased continental-margin slumping frequency during sea level lowstands above gas hydrate-bearing sediments. Geology, 24, 143-146, doi: 10.1130/0091-76 13(1996)024<0143:ICMSFD>2.3.CO;2. [Link]

Poulos, H. G., 1988: Marine geotechnics, Unwin Hyman, London, $473 \mathrm{pp}$.

Randolph, M. F., 2004: Characterisation of soft sediments for offshore applications. In: Da Fonseca, A. V. and P. W. Mayne (Eds.), Proceedings ISC-2 on Geotechnical 
and Geophysical Site Characterization, Rotterdam, The Netherlands, 209-232.

Ten Brink, U. S., H. J. Lee, E. L. Geist, and D. Twichell, 2009: Assessment of tsunami hazard to the US East Coast using relationships between submarine land- slides and earthquakes. Mar. Geol., 264, 65-73, doi: 10.1016/j.margeo.2008.05.011. [Link]

Van Den Berg, A. P., 1984: Developments in static cone penetrometering of the seabed. Underwater Systems Design, 6, 28-31. 